\title{
Inherited Platelet Function Disorder From Novel Mutations in RAS Guanyl-Releasing Protein-2 Confirmed by Sanger Sequencing
}

\author{
Abdulqader Al-Hebshi 1, 2, 3, 4
}

1. Pediatric Hematology Oncology, Prince Mohammed Bin Abdulaziz Hospital, Medina, SAU 2. Pediatric Hematology Oncology, Ministry of National Guard Health Affairs, Medina, SAU 3. Pediatric Hematology Oncology, King Abdullah International Medical Research Center, Riyadh, SAU 4. Pediatric Hematology Oncology, King Saud Bin Abdulaziz University for Health Sciences, Riyadh, SAU

Corresponding author: Abdulqader Al-Hebshi, habshi05@hotmail.com

\begin{abstract}
Inherited platelet disorders (IPDs) are genetically heterogeneous rare disorders due to quantitative and/or qualitative abnormalities of the platelet. IPDs are often predisposed to significant medical complications. RAS guanyl-releasing protein-2 (RASGRP2) was recently identified as a gene affected in patients with platelet function defects and a bleeding complication. RASGRP2 codes for the protein CalDAG-GEFI RAS (guanyl-releasing protein-2), a guanine nucleotide exchange factor for small guanosine triphosphate(GTP)ase Rap1. We used Sanger sequencing to identify a novel function-disrupting homozygous mutation in RASGRP2 responsible for bleeding diathesis and platelet dysfunction in a patient.
\end{abstract}

Categories: Pediatrics, Hematology

Keywords: inherited platelet disorder, rasgrp2, platelet dysfunction

\section{Introduction}

Genetic defects of platelets constitute rare diseases [1], which affect the platelet number and function and often cause severe bleeding and other significant medical complications encountered in clinical practice [2]. The presentation may be variable platelet counts and bleeding episodes, complicating the diagnosis [3]. Identification of the underlying genetic defects in these disorders is complicated by the differences in the clinical expression of the bleeding symptoms in affected individuals [4]. Also, it is problematic to establish the diagnosis based solely on function studies because, due to limited stability, immediate testing on fresh patient platelets is required. It is essential to use more advanced genetic testing such as next-generation sequencing, to be able to make an accurate diagnosis based on genetic information [5-6].

Review began 10/27/2020 Review ended 11/21/2020 Published 11/25/2020

\section{(c) Copyright 2020}

Al-Hebshi. This is an open access article distributed under the terms of the Creative Commons Attribution License CC-BY 4.0., which permits unrestricted use, distribution, and reproduction in any medium, provided the original author and source are credited.
Glanzmann's thrombasthenia is one of the most severe inherited platelet function disorders caused by recessive mutations in either integrin alpha-IIb (ITGA2B) or integrin beta chain beta 3 (ITGB3) leading to defects in the $\alpha \operatorname{IIb} \beta 3$ integrin and consequently to severely impaired platelet aggregation. RAS guanylreleasing protein-2 (RASGRP2) was recently identified as a gene affected in patients with a platelet function defect and a bleeding complication [7-8]. It is strongly expressed in platelets and neutrophils, where its encoded protein CalDAG-GEFI facilitates the activation of Rap1 and subsequent activation of integrins [910]. A pathogenic variant in RASGRP2 has been associated with platelet-type bleeding disorder type 18 (OMIM: 615888). It is an autosomal recessive, nonsyndromic platelet function disorder that is associated with moderate or severe bleeding, similar to other disorders of the $\alpha \operatorname{IIb} \beta 3$ integrin [11].

To the extent of my knowledge this is the first case in Saudi Arabia that case reports the novel pathogenic RASGRP2 mutation c956C $>$ T. (Pro319Leu) which is considered one of the causative variants for this rare autosomal recessive platelet-type bleeding disorder type 18 (BDPLT18).

\section{Case Presentation}

A three-year-old Saudi girl, with no known chronic illness, presented on the 2nd of October 2017 at the Emergency Room at Prince Mohammed Bin Abdulaziz Hospital, Ministry of National Guard Health Affairs, Medina, Saudi Arabia. She was accompanied by her parents, with a bilateral profuse non-stopping epistaxis lasting for a few hours. There was no bleeding from other orifices, she was conscious, alert, oriented, and calm, with normal vital signs (temperature $36.6^{\circ} \mathrm{C}$, respiratory rate 24 /minute, oxygen saturation $96 \%$ on room air, heart rate 110 beats/minute, and blood pressure 121/77 $\mathrm{mmHg}$ ), not dysmorphic, and was not cyanosed or distressed. She was bleeding actively (epistaxis) and there were multiple ecchymoses over her upper and lower extremities (Figure 1,2) and abdomen with different colors and sizes. There was no hepatosplenomegaly or lymphadenopathy. Other systemic examinations were unremarkable. There was no history of trauma or drug ingestion. Another systemic review was unremarkable. After vomiting a large amount of digested blood, becoming paler and symptomatic with increased tachycardia, her hemoglobin started to drop from $11.5 \mathrm{~g} / \mathrm{dl}$ to $8 \mathrm{~g} / \mathrm{dl}$ (other complete blood count (CBC) indices remained normal), so she 


\section{Cureus}

was transfused with packed red blood cells, fresh frozen plasma, as well as recombinant Factor VII, which were administrated to treat the symptomatic anemia and to stop the severe uncontrolled epistaxis. The Ear Nose and Throat team were consulted and they found multiple bleeding vessels, which were cauterized locally. Almost all bleeding completely stopped six hours post-admission.

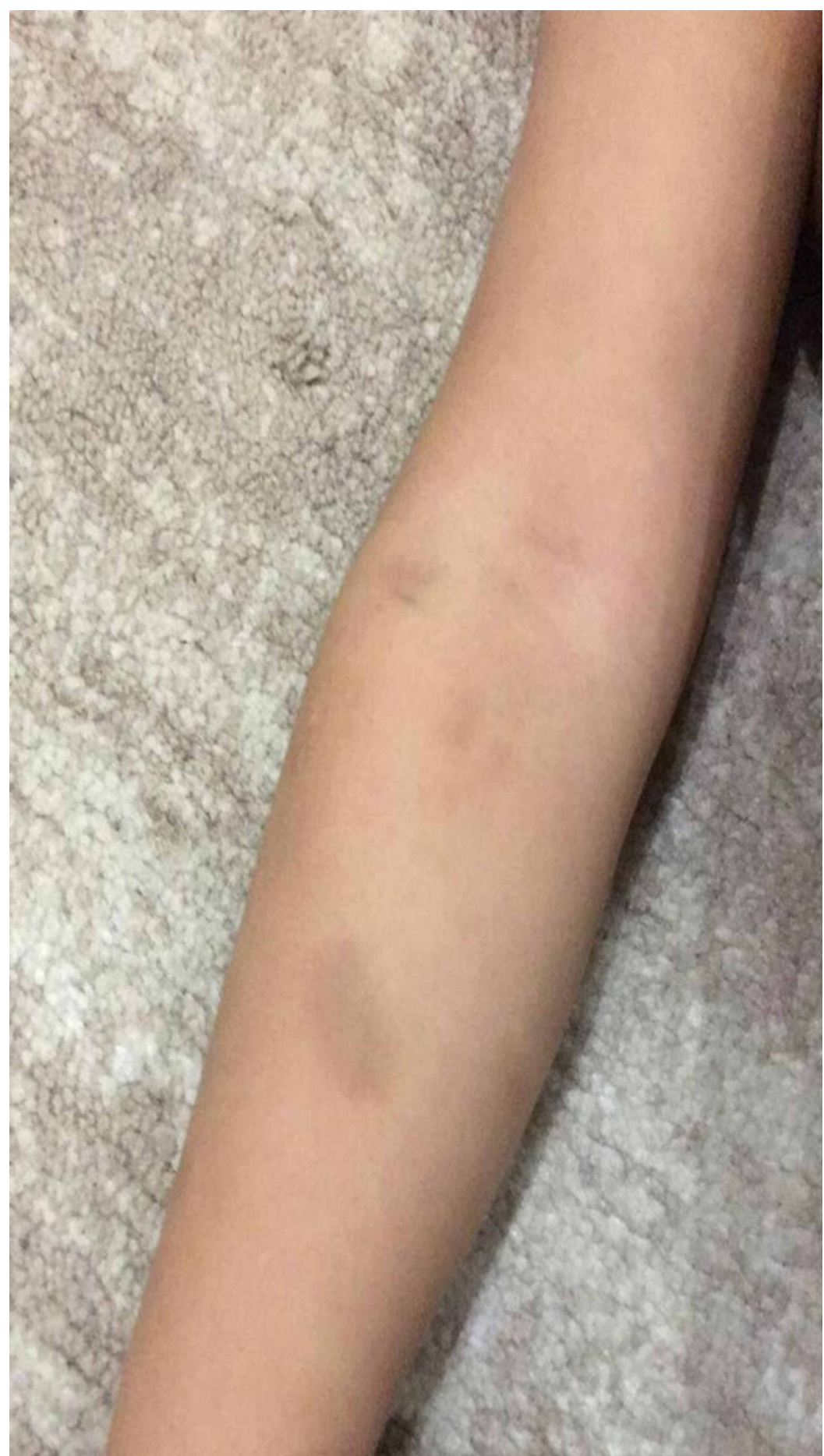

FIGURE 1: Shows multiple ecchymosis over the upper extremity 


\section{Cureus}

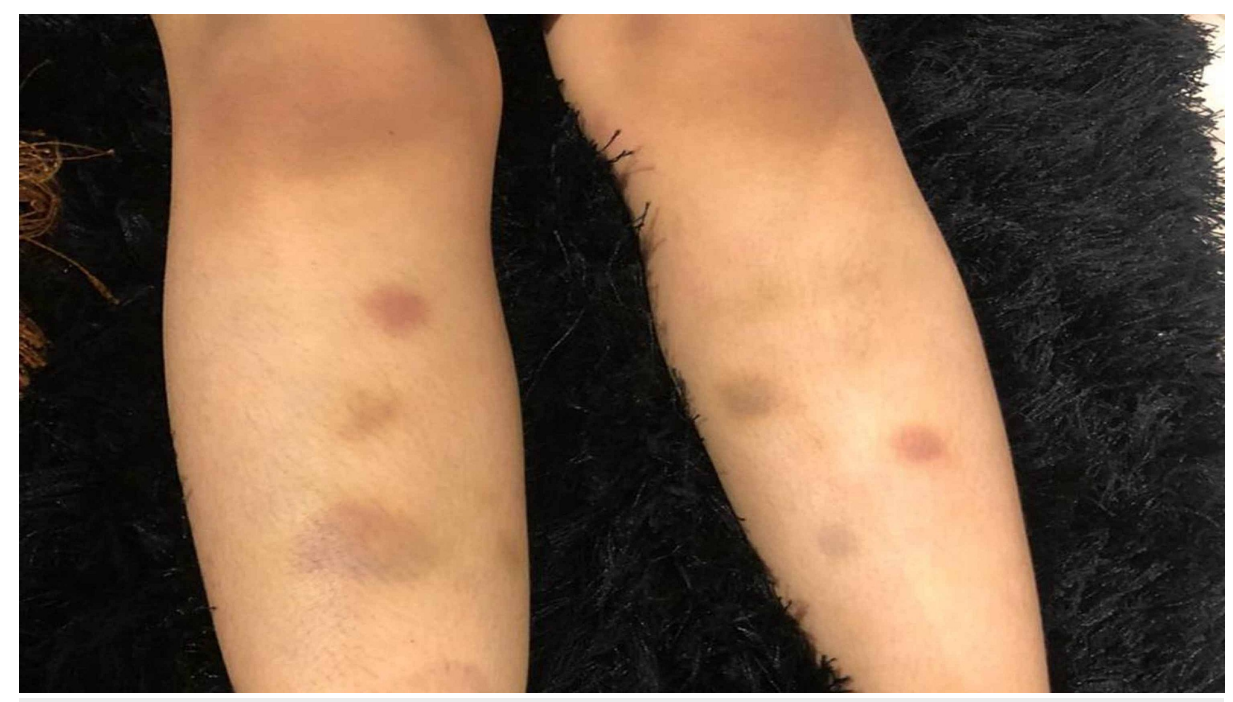

FIGURE 2: Shows multiple ecchymosis over the lower extremity

The patient is a product of a full-term pregnancy, with a spontaneous vaginal delivery, no neonatal intensive care unit (NICU) admission, not known to have any chronic illness, not on any medication, and never received a blood transfusion before. There was a history of prolonged wound healing and profuse bleeding due to minimal injuries at the age of six months. Her parents are cousins and she has two siblings, all are healthy, with no family history of bleeding disorders.

Glanzmann thrombasthenia (GT) had initially been suspected, as this type of platelet dysfunction is common in our region. An initial bleeding-related work-up was done including CBC. The coagulation profile showed a normal platelet count, normal partial thromboplastin time (PTT), international normalized ratio (INR), normal Factor XIII, and the von Willebrand factor (VWF) panel was normal (Table 1, 2). Flow cytometry was done to rule out GT, which was normal. ITGA2B, ITGB3, and VWF gene sequencing were done and no relevant variant was detected. A platelet aggregation study (more than one reading) revealed a normal response to ristocetin and arachidonic acid but had an abnormal response to collagen, adenosine diphosphate (ADP), and epinephrine (Table 3). The peripheral blood smear was normal.

\begin{tabular}{|c|c|c|}
\hline Test & Result & Reference range \\
\hline WBC & $13.9 \times 10^{9} / \mathrm{L}$ & $\left(5-12 \times 10^{9} \mathrm{cells} / \mathrm{L}\right)$ \\
\hline $\mathrm{RBC}$ & $4.25 \times 10^{12} / \mathrm{L}$ & $\left(3.90-5.60 \times 10^{12} / L\right)$ \\
\hline $\mathrm{Hgb}$ & $11.5 \mathrm{~g} / \mathrm{dl}$ & (12 to $16 \mathrm{~g} / \mathrm{dL}$ ) \\
\hline Hct & $0.360 \mathrm{~L} / \mathrm{L}$ & (0.310-.450 L/L) \\
\hline Platelet & $469 \times 10^{9} / \mathrm{L}$ & $\left(150-450 \times 10^{9}\right.$ cells/L) \\
\hline
\end{tabular}

\section{TABLE 1: Complete blood count (CBC).}

WBC, white blood cell; RBC, red blood cell; Hb, hemoglobin; Hct, hematocrit. 


\section{Cureus}

\begin{tabular}{|c|c|c|}
\hline Test & Result & Reference range \\
\hline Epinephrine aggregation & $5 \%$ & $(70-90 \%)$ \\
\hline Arachidonic Acid & $81 \%$ & $(70-90 \%)$ \\
\hline Collagen aggregation & $3 \%$ & $(70-90 \%)$ \\
\hline Adenosine Deaminase & $9 \%$ & $(70-90 \%)$ \\
\hline Ristocetin & $84 \%$ & $(70-90 \%)$ \\
\hline
\end{tabular}

TABLE 2: Platelets aggregation test.

\begin{tabular}{|c|c|c|}
\hline Test & Result & Reference range \\
\hline VWF Ag & $65 \%$ & $(50-150 \%)$ \\
\hline VW Ristocetin Cofactor & $59 \%$ & $(50-200 \%)$ \\
\hline Factor VIII & $97 \mathrm{u} / \mathrm{ml}$ & $(50-150 \%)$ \\
\hline PTT & $32 \mathrm{sec}$ & (26-41 seconds) \\
\hline PT & $12 \mathrm{sec}$ & $(11.0-14.5 \mathrm{sec})$ \\
\hline INR & $1 \%$ & $(0.8-1.2 \%)$ \\
\hline Factor XIII & $83 \mathrm{u} / \mathrm{ml}$ & $(70-140 \%)$ \\
\hline Thrombin time & $18.3 \mathrm{sec}$ & (14-19 sec) \\
\hline Fibrinogen & $2.5 \mathrm{~g} / \mathrm{L}$ & $(2-4 \mathrm{~g} / \mathrm{L})$ \\
\hline
\end{tabular}

TABLE 3: Coagulation profile.

VWF Ag, von Willebrand factor antigen; PTT, partial thromboplastin time; PT, prothrombin time; INR, international normalized ratio

The results of a genetic study (performed at Bioscientia Human Genetics, Ingelheim, Germany) identified a homozygous RASGRP2 VUS c.956 C>T p. (pro 319leu) which confirmed the diagnosis of BDPLT18, and based on this final genetic result, we recommended checking all the family members for the same gene. We found that all the other family members are heterozygous carriers of the same familial RASGRP2 VUS.

\section{Discussion}

The biallelic pathogenic variant in RASGRP2 has been associated with platelet-type bleeding disorder type 18. It is an autosomal recessive, nonsyndromic platelet function disorder that is associated with moderate or severe bleeding, similar to other disorders of the $\alpha \operatorname{Ibb} \beta 3$ integrin. There is a consistent laboratory phenotype of reduced aggregation response to adenosine $5^{\prime}$-diphosphate (ADP) and epinephrine, but no defect in dense granule secretion, distinguishing this disorder from $\delta$-storage disease [11].

Pathogenic RASGRP2 variants are causative for autosomal recessive platelet-type bleeding disorder type 18 (BDPLT18) gene (605577) on chromosome 11q13. It is a rare hematological disease due to a CalDAG-GEFI deficiency (OMIM ${ }^{\circledR 615888)}$. With a prevalence of $<1 / 1000000$ globally, the age of onset and the clinical course are observed in the infancy period. According to our literature review, Canault et al. reported three siblings, born of consanguine parents, with a bleeding disorder due to defective platelet function [1]. The patient developed mucocutaneous bleeding around 18 months of age. Features included epistaxis, hematomas, bleeding after tooth extraction, and menorrhagia. Bleeding times were increasing, and the patient's platelets indicated a reduced aggregation in response to ADP or epinephrine. Canault et al. identified a homozygous mutation in the RASGRP2 gene (G248W; 605577.0001). The mutation was found by exome sequencing and segregated with the disorder in the family [12].

With the current case, we report a novel pathogenic RASGRP2 mutation c956C >T. (Pro319Leu) which causes an amino acid change from Pro to Leu at position 319. During the first presentation of our patient, Glanzmann thrombasthenia was initially suspected as the mother has a history of oozing after a cut wound 
but the sequencing analysis of ITGA2B, ITGB3 as well as von Willebrand gene was normal [13]. Further work was done using Clinical Exome Sequencing, which revealed a potential positive result for a variant of uncertain significance, which has been confirmed by Sanger sequencing as a homozygous variant of uncertain significance with the parents being carriers of the same variant. Consequently, the diagnosis of an autosomal recessive platelet-type bleeding 18 with the novel mutation was confirmed [14]. This type of variant was classified as a variant of uncertain significance (class 3) according to the recommendations of Centogene and ACMG (American College of Medical Genetics) (Table 4) [15].

\begin{tabular}{|l|l|}
\hline Class1 & Pathogenic \\
\hline Class2 & Likely pathogenic \\
Class3 & Variant of uncertain significance (VUS) \\
Class 4 & Likely benign \\
Class 5 & Benign \\
\hline TABLE 4: Centogene Variant classification (Based on American College of Medical Genetics \\
\hline recommendations). \\
\hline \hline
\end{tabular}

\section{Conclusions}

RAS guanyl-releasing protein-2 (RASGRP) variant c956C >T. (Pro319Leu) is uncommon cause of autosomal recessive platelet-type bleeding disorder type 18 (BDPLT18). This case was reported because of the rarity of such mutations affecting platelet dysfunction and aggregation causing hemostasis disorder.

I recommend performing RASGRP2 gene testing after excluding the common inherited platelet disorders (IPDs) like Glanzmann thrombasthenia because early detection of such rare causes will enable the physician to know the nature of the disease and how to anticipate the severity in comparison with other IPDs.

\section{Additional Information \\ Disclosures}

Human subjects: Consent was obtained by all participants in this study. Conflicts of interest: In compliance with the ICMJE uniform disclosure form, all authors declare the following: Payment/services info: All authors have declared that no financial support was received from any organization for the submitted work. Financial relationships: All authors have declared that they have no financial relationships at present or within the previous three years with any organizations that might have an interest in the submitted work. Other relationships: All authors have declared that there are no other relationships or activities that could appear to have influenced the submitted work.

\section{Acknowledgements}

The author gratefully acknowledges Dr. Talal Al Harbi from King Abdullah Specialist Children Hospital, Riyadh (KASCH) for his support and help.

\section{References}

1. Canault M, Ghalloussi D, Grosdidier C, et al.: Human CalDAG-GEFI gene (RASGRP2) mutation affects platelet function and causes severe bleeding. J Exp Med. 2014, 211:1349-1362. 10.1002/ajh.24917

2. Romasko EJ, Devkota B, Biswas S, et al.: Utility and limitations of exome sequencing in the molecular diagnosis of pediatric inherited platelet disorders. Am J Hematol. 2018, 93:8-16. 10.1002/ajh.24917

3. Lambert MP: Inherited platelet disorders: a modern approach to evaluation and treatment . Hematol Oncol Clin North Am. 2019, 33:471-487. 10.1016/j.hoc.2019.01.008

4. Leo VC, Morgan NV, Bem D, et al.: Use of next-generation sequencing and candidate gene analysis to identify underlying defects in patients with inherited platelet function disorders. J Thromb Haemost. 2015, 13:643-650. 10.1111/jth.12836

5. Lentaigne C, Freson K, Laffan MA, et al.: Inherited platelet disorders: toward DNA-based diagnosis . Blood. 2016, 127:2814-23. 10.1182/blood-2016-03-378588

6. Bastida JM, Lozano ML, Benito R, et al.: Introducing high-throughput sequencing into mainstream genetic diagnosis practice in inherited platelet disorders. Haematologica. 2018, 103:148-162. 10.3324/haematol.2017.171132

7. Nurden AT, Pillois X, Fiore M, et al.: Expanding the mutation spectrum affecting alIbb3 integrin in glanzmann thrombasthenia: screening of the ITGA2B and ITGB3 genes in a large international cohort. Hum Mutat. 2015, 36:548-561. 10.1002/humu.22776

8. Chrzanowska-Wodnicka M, Smyth SS, Schoenwaelder SM, Fischer TH, White GC: Rap1b is required for 


\section{Cureus}

normal platelet function and hemostasis in mice. J Clin Invest. 2005, 115:680-687. 10.1172/JCI22973

9. Lozano ML, Cook A, Bastida JM, et al.: Novel mutations in RASGRP2, which encodes CalDAG-GEFI, abrogate Rap1 activation, causing platelet dysfunction. Blood. 2016, 128:1282-1289. 10.1182/blood-2015-11-683102

10. Bolton-Maggs PH, Chalmers EA, Collins PW, et al.: A review of inherited platelet disorders with guidelines for their management on behalf of the UKHCDO. Br J Haematol. 2006, 135:603-633. 10.1111/j.13652141.2006.06343.x

11. Westbury SK, Canault M, Greene D, et al.: Expanded repertoire of RASGRP2 variants responsible for platelet dysfunction and severe bleeding. Blood. 2017, 130:1026-1030. 10.1182/blood-2017-03-776773

12. Yun JW, Lee K-O, Jung CW, Oh S-Y, Kim S-H, Choi CW, Kim H-J: Hereditary platelet function disorder from RASGRP2 gene mutations encoding CalDAG-GEFI identified by whole-exome sequencing in a Korean woman with severe bleeding. Haematologica. 2019, 104:274-276. 10.3324/haematol.2019.218487

13. Haghighi A, Borhany M, Ghazi A, et al.: Glanzmann thrombasthenia in Pakistan: molecular analysis and identification of novel mutations. Clin Genet. 2016, 89:187-192. 10.1111/cge.12622

14. Lee H, Deignan JL, Dorrani N, et al.: Clinical exome sequencing for genetic identification of rare mendelian disorders. JAMA. 2015, 312:1880-1887. 10.1001/jama.2014.14604

15. Richards S, Aziz N, Bale S, et al.: Standards and guidelines for the interpretation of sequence variants: a joint consensus recommendation of the American College of Medical Genetics and Genomics and the Association for Molecular Pathology. Genet Med. 2015, 17:405-423. 10.1038/gim.2015.30 